\title{
Statistical Approach to the Drug-Induced Taste Disorders Based on Zinc Chelating Ability
}

\author{
Takashi FuKasAwa, ${ }^{a}$ Takao ORII, ${ }^{b}$ Masayo TANAKA, ${ }^{b}$ \\ Seiji YANO, ${ }^{c}$ Noriko SUZUKI, ${ }^{d}$ and Yasushi KANZAKI ${ }^{*}, d$ \\ Pharmacy Department, Saiseikai Yokohamashi Nanbu Hospital, ${ }^{a}$ 3-2-10 Konandai, Konan-ku, Yokohama \\ 234-8503, Japan, Pharmacy Department, Kanto Medical Center NTT EC, ${ }^{b}$ 5-9-22 Higashi-Gotanda, \\ Shinagawa-ku, Tokyo 141-8625, Japan, FCG Research Institute Incorporation, ${ }^{c}$ 3-32-42 \\ Higashi-Shinagawa, Shinagawa, Tokyo 140-0002, Japan, and Showa Pharmaceutical \\ University, ${ }^{d}$ 3-3165 Higashi-Tamagawagakuen, Machida, Tokyo 194-8543, Japan
}

(Received August 13, 2004; Accepted December 17, 2004)

\begin{abstract}
Various drug-induced taste disorders have been ascribed to zinc deficiency in serum. Assuming that the zinc deficiency is caused by the chelating reaction of zinc ions with drugs, the electrode potential of the $\mathrm{Zn}^{2+} / \mathrm{Zn}(\mathrm{Hg})$ system was measured in the presence of drugs in water, ethanol, and $N, N$-dimethylformamide (DMF). The zinc-chelating ability was estimated based on the potential change $\Delta E_{2}$ with the addition of a drug. A large potential change suggesting potent chelating ability was observed in penicillamine, furosemide, and ibuprofen in ethanol and in fluorouracil, acetazolamide, and bezafibrate in DMF. Multiple regression analysis was used to evaluate the observed $\Delta E_{2}$ in $\mathrm{mV}$ to represent chelating ability. The regression equation to estimate the frequency of taste disorders was deduced from $\Delta E_{2}$, and frequency of four drugs appeared in package inserts and interview forms. According to the regression equation, the frequency of taste disorders was successfully estimated for 14 drugs examined in this study. The result was examined in a clinical case.
\end{abstract}

Key words__ zinc amalgam electrode; taste disorder; drug-induced disorder; zinc chelate; multivariate analysis

\section{INTRODUCTION}

Decreasing the incidence of taste disorders is an important problem to improve the quality of life of many patients. Abnormal tastes are interpreted as unpleasant or completely different from the characteristics of a particular food or chemical compound. ${ }^{1)}$ Various complaints have been documented in taste aberration (dysgeusia), described as metallic, salty, bitter, sweet, sour, etc. There are numerous causes of taste disorder such as aging, radiation, lack of oral hygiene, vitamin $\mathrm{B}$ deficiency, zinc deficiency, and numerous drugs. ${ }^{2)}$ The most frequent cause is drug-induced taste disorder according to an epidemiologic survey on the cause of dysgeusia in 2,278 patients ${ }^{3)}$ who visited Nihon University Hospital Taste Clinic over the decade from 1981 to 1990 . The side effects of drugs was responsible for the largest proportion, $21.7 \%$ (495 patients), followed by idiopathic taste disorder (15.0\%, 341 patients) as shown in Table 1. Figure 1 shows the various types of drug-induced taste disorder printed in package inserts for 190.4)

e-mail: kanzaki@ac.shoyaku.ac.jp
Frequency of drug-induced taste disorders is also mentioned in interview forms. However, the relationship of most drugs with taste disorders is described as "unclear" or "no mention." Despite the various complaints stated above, few systematic studies have been conducted on the mechanisms of drug-induced taste disorders.

Qualitative proposals have been reported on the drug-induced taste disorder related to zinc deficiency. The first reports by Prasad et al. mentioned zinc deficiency in humans. ${ }^{5,6)}$ They noted that zinc ions are closely associated with certain metalloenzymes such as metal-requiring enzymes, hormones, and vitamins. Tarui $\left.{ }^{7}{ }^{7} 8\right)$ treated experimental animals with chelating agents such as EDTA and 8-oxyquinoline and their derivatives. They found an increase in urinary zinc when the chelating agent was incorporated in the living organism, while only slight changes in the concentration in urinary iron and copper were observed. These findings suggested that a transfer of zinc ions from the serum albumin to the chelating agent occurred, followed by excretion into the urine. Henkin and Bradly ${ }^{9)}$ proposed the mechanism of zinc ion chelation by $D$-penicillamine as a possible cause of taste disorder. Later, Sekimoto and Tomita ${ }^{10)}$ and 
Table 1 Causes of Taste Disorder in 2,278 Patients (1981 to 1990) ${ }^{3)}$

\begin{tabular}{lccr}
\hline \hline \multicolumn{1}{c}{ Cause } & $\begin{array}{c}\text { Men } \\
\text { No. } \%)\end{array}$ & $\begin{array}{c}\text { Women } \\
\text { No.(\%) }\end{array}$ & $\begin{array}{c}\text { Total } \\
\text { No.(\%) }\end{array}$ \\
\hline Drug-induced & $219(25.1)$ & $276(19.6)$ & $495(21.7)$ \\
Idiopathic & $148(17.0)$ & $193(13.7)$ & $341(15.0)$ \\
Zinc deficiency & $119(13.7)$ & $211(15.0)$ & $330(14.5)$ \\
Psychogenetic & $63(7.2)$ & $180(12.8)$ & $243(10.7)$ \\
Flavor disorder & $54(6.2)$ & $117(8.3)$ & $171(7.5)$ \\
Systematic disease & $61(7.0)$ & $108(7.7)$ & $169(7.4)$ \\
Oral disease & $49(5.6)$ & $97(6.9)$ & $146(6.4)$ \\
Postinfluenza taste-and-smell disorder & $15(1.7)$ & $45(3.2)$ & $60(2.6)$ \\
Peripheral nerve disorder & $24(2.8)$ & $35(2.5)$ & $59(2.6)$ \\
Central & $20(2.3)$ & $18(1.3)$ & $38(1.7)$ \\
Endocrine disorder & $9(1.0)$ & $14(1.0)$ & $23(1.0)$ \\
Other & $90(10.3)$ & $113(8.0)$ & $203(8.9)$ \\
Total & $871(100)$ & $1,407(100)$ & $2,278(100)$ \\
\hline
\end{tabular}

Note: Including overlapped cases.

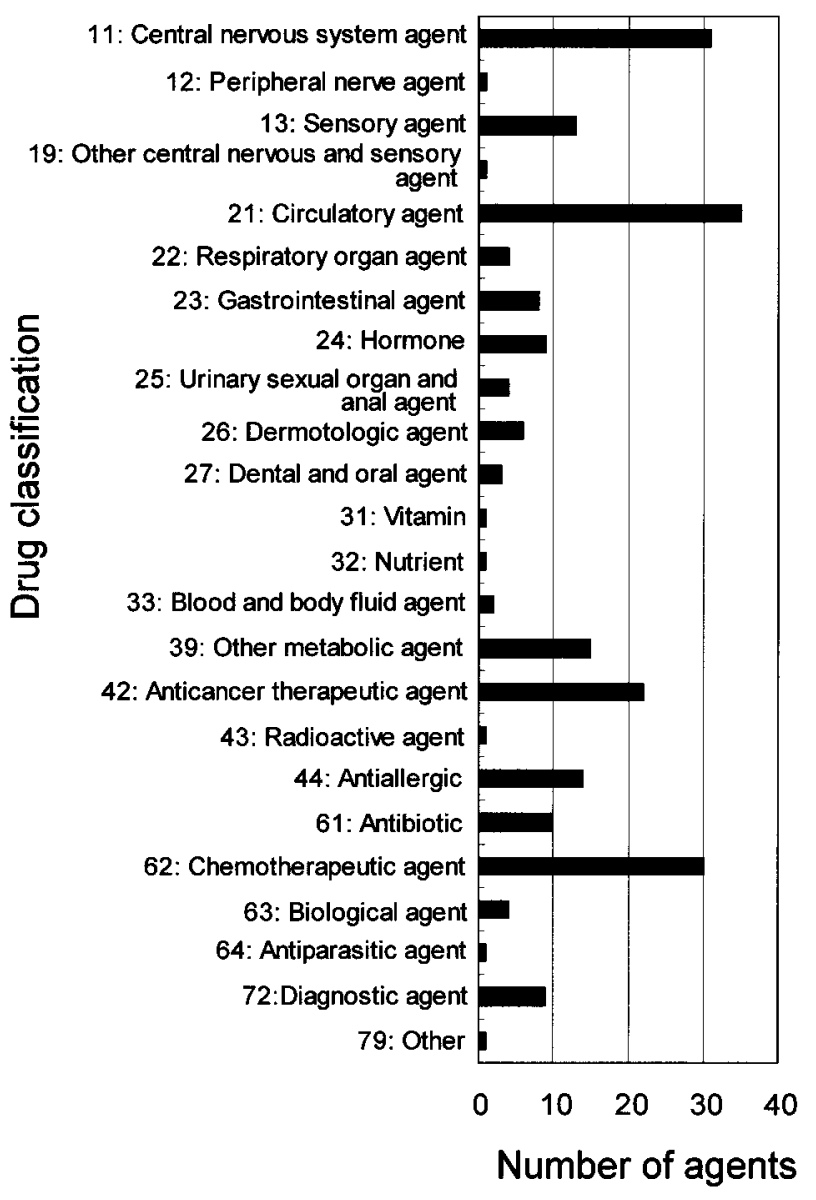

Fig. 1. Classification of Drugs that may Induce Taste Disorders as Listed in Package Inserts

*The prefix number means the classification number of drugs according to Drugs in Japan CD-ROM.4)
Haga and Tomita ${ }^{11)}$ demonstrated that drug-induced taste disorder may be ascribed to zinc chelation by seven drugs including methyldopa.

Zinc exists in abundance in the taste buds of the tongue. Tomita ${ }^{12,13)}$ reported the mechanism of druginduced taste disorders. He found that zinc deficiency prevented neogenesis and regeneration of the taste buds within 10 days. When the internal zinc level was reduced using a chelating drug, a taste disorder was induced. He suggested that the long-term use of drugs with chelating ability could cause increased excretion of urinary zinc, resulting in zinc deficiency.

Sekimoto and Tomita $^{10)}$ reported the stability constant of zinc ions with furosemide and captopril in dioxan solvent using polarography. However, little information on the chelating ability of zinc ions is now available either in package inserts or interview forms. Because of the lack of experimental studies on the chelating ability of drugs with zinc ions, we first planned to establish a reliable and simple experimental procedure to measure the chelating ability of drugs with zinc ions. The second aim was to establish a statistical multivariate procedure to predict quantitatively the frequency of taste disorders by connecting the zinc-chelating ability with drugs based on the experimental value. If zinc deficiency were really the main cause of the taste disorder, the statistical data described in the package inserts and interview forms ${ }^{14}$ ) could be improved using the multivariate procedure. 


\section{MATERIALS AND METHOD}

Theoretical Base and Apparatus for Potential Measurement The potential measurement of a zinc amalgam electrode, $\mathrm{Zn}^{2+} / \mathrm{Zn}(\mathrm{Hg})$, was performed to evaluate the zinc-chelating ability of drugs as follows. Zinc amalgam instead of zinc metal was adopted in this study to improve the stability as well as reproducibility. The electrode reaction of zinc ion/zinc amalgam system is

$$
\mathrm{Zn}^{2+}+2 \mathrm{e}^{-}=\mathrm{Zn}(\mathrm{Hg})
$$

where $\mathrm{Zn}(\mathrm{Hg})$ is the zinc amalgam. In the following equation, however, the symbol $\mathrm{Zn}$ is used instead of $\mathrm{Zn}(\mathrm{Hg})$ for convenience. The Nernst equation for the electrode reaction (1) is

$$
E_{\left(\mathrm{Zn}^{2+} / \mathrm{Zn}\right)}=E_{\left(\mathrm{Zn}^{2+} / \mathrm{Zn}\right)}^{0}+\frac{R T}{2 F} \cdot \ln \left[\mathrm{Zn}^{2+}\right]
$$

where $E_{\left(\mathrm{Zn}^{2+} / \mathrm{Zn}\right)}$ is the observed electrode potential, $E_{\left(\mathrm{Zn}^{2+} / \mathrm{Zn}\right)}^{0}$ the standard electrode potential of the $\mathrm{Zn}^{2+}$ /Zn system, $R$ the gas constant, $T$ the thermodynamic temperature, $F$ the Faraday constant, and [ ] indicates molar concentration.

The chelating reaction of a drug (symbol L) with a zinc ion is represented as follows if $m$ is the number of neutral drugs coordinated with one zinc ion.

$$
\mathrm{Zn}^{2+}+m \mathrm{~L}=\mathrm{ZnL}_{m}^{2+}
$$

The stability constant $K$ in Eq. (3) is indicated by

$$
K=\frac{\left[\mathrm{ZnL}_{m}^{2+}\right]}{\left[\mathrm{Zn}^{2+}\right][\mathrm{L}]^{m}}
$$

By substituting Eq. (4) into Eq. (2), the following relation is deduced.

$$
\begin{aligned}
E_{\left(\mathrm{ZnL}_{m}^{2+} / \mathrm{Zn}\right)} & =E_{\left(\mathrm{Zn}^{2+} / \mathrm{Zn}\right)}^{0}+\frac{R T}{2 F} \cdot \ln \left[\mathrm{ZnL}_{m}^{2+}\right] \\
& -\frac{m R T}{2 F} \cdot \ln [\mathrm{L}]-\frac{R T}{2 F} \cdot \ln K \\
& =E_{\left(\mathrm{ZnL}_{m}^{2+} / \mathrm{Zn}\right)}^{0}+\frac{R T}{2 F} \cdot \ln \left[\mathrm{ZnL}_{m}^{2+}\right] \\
& -\frac{m R T}{2 F} \cdot \ln [\mathrm{L}]
\end{aligned}
$$

where

$$
E_{\left(\mathrm{ZnL}_{m}^{2+} / \mathrm{Zn}\right)}^{0}=E_{\left(\mathrm{Zn}^{2+} / \mathrm{Zn}\right)}^{0}-\frac{R T}{2 F} \cdot \ln K
$$

If $K$ is very large and $[\mathrm{L}] \gg\left[\mathrm{Zn}^{2+}\right]$, the stability constant $K$ is deducible by measuring the [L] dependence of the electrode potential of $E_{\left(\mathrm{ZnL}_{m}^{2+} / \mathrm{Zn}\right)}$ according to Eqs. (5) and (6). Under such conditions, the equilibrium of Eq. (3) inclines to the right, i.e., $\left[\mathrm{ZnL}_{m}^{2+}\right] \gg\left[\mathrm{Zn}^{2+}\right]$. However, two experimental problems disturb the application of Eqs.
(5) and (6). One is the case when $K$ is rather small and the condition $\left[\mathrm{ZnL}_{m}^{2+}\right] \gg\left[\mathrm{Zn}^{2+}\right]$ is barely satisfied. The other is when the reliable Nernst plot based on Eq. (5) was hard to measure and the condition $[\mathrm{L}] \gg\left[\mathrm{Zn}^{2+}\right]$ was not satisfied because most drugs had very low solubility in aqueous solution. Under such condition, we cannot obtain the theoretical Nernst slope, $-m R T / 2 F$ in Eq. (5), and estimate the stability constant $K$. Such problems could be overcome to estimate the drug-chelating ability using the potential change when a known amount of drug is added to the $\mathrm{Zn}^{2+} / \mathrm{Zn}(\mathrm{Hg})$ system instead of $K$.

The experimental apparatus used for measuring the electrode potential of $\mathrm{Zn}^{2+} / \mathrm{Zn}(\mathrm{Hg})$ is illustrated in Fig. 2. The electrode potential was measured versus an $\mathrm{Ag} / \mathrm{AgCl}$ reference electrode using a commercially available digital voltmeter with a sensitivity of 0.01 $\mathrm{mV}$. An agar salt bridge was prepared using $\mathrm{KNO}_{3}$ to avoid the leakage of $\mathrm{Cl}^{-}$and resulting formation of insoluble $\mathrm{Hg}_{2} \mathrm{Cl}_{2}$. A pH meter equipped with a glass electrode was used (model HM-60G, Toa DKK Ltd., Japan). A zinc amalgam electrode was used as a working electrode. It was prepared by dipping a zinc piece fixed on a platinum wire into a small mercury pool for a few seconds. The zinc-amalgam electrode was used promptly after preparation to measure the electrode potential.

Reagents Deionized water was prepared using ion-exchange resins and a filtering system (Puric Model-R, Japan Organo Co., Ltd., Japan). Zinc pieces for volumetric analysis were supplied by Wako Pure Chemical Industries Ltd., Japan. Mercury was purified sufficiently by aeration in $0.1 \mathrm{~mol} / 1 \mathrm{HNO}_{3}$ solution. Commercially available purified nitrogen gas was used to remove the dissolved oxygen (Itotchu High Tension Gas Co., Ltd.) . All other reagents used were of reagent grade.

Drug Samples The drugs examined were selected referring to "Drugs in Japan" CD-ROM (2002 April edition) .4) Key words for searching were "taste" and "internal drugs." All drugs for which the package inserts mentioned taste disorders in the side effects were counted. The drugs selected among the 150 drugs are listed in Table 2. Drugs inhaled into or applied in the mouth were excluded from this study because they disturb the taste-sensitive cells directly. Because of the poor solubility of drugs in aqueous solution, most test solutions of drugs were prepared 


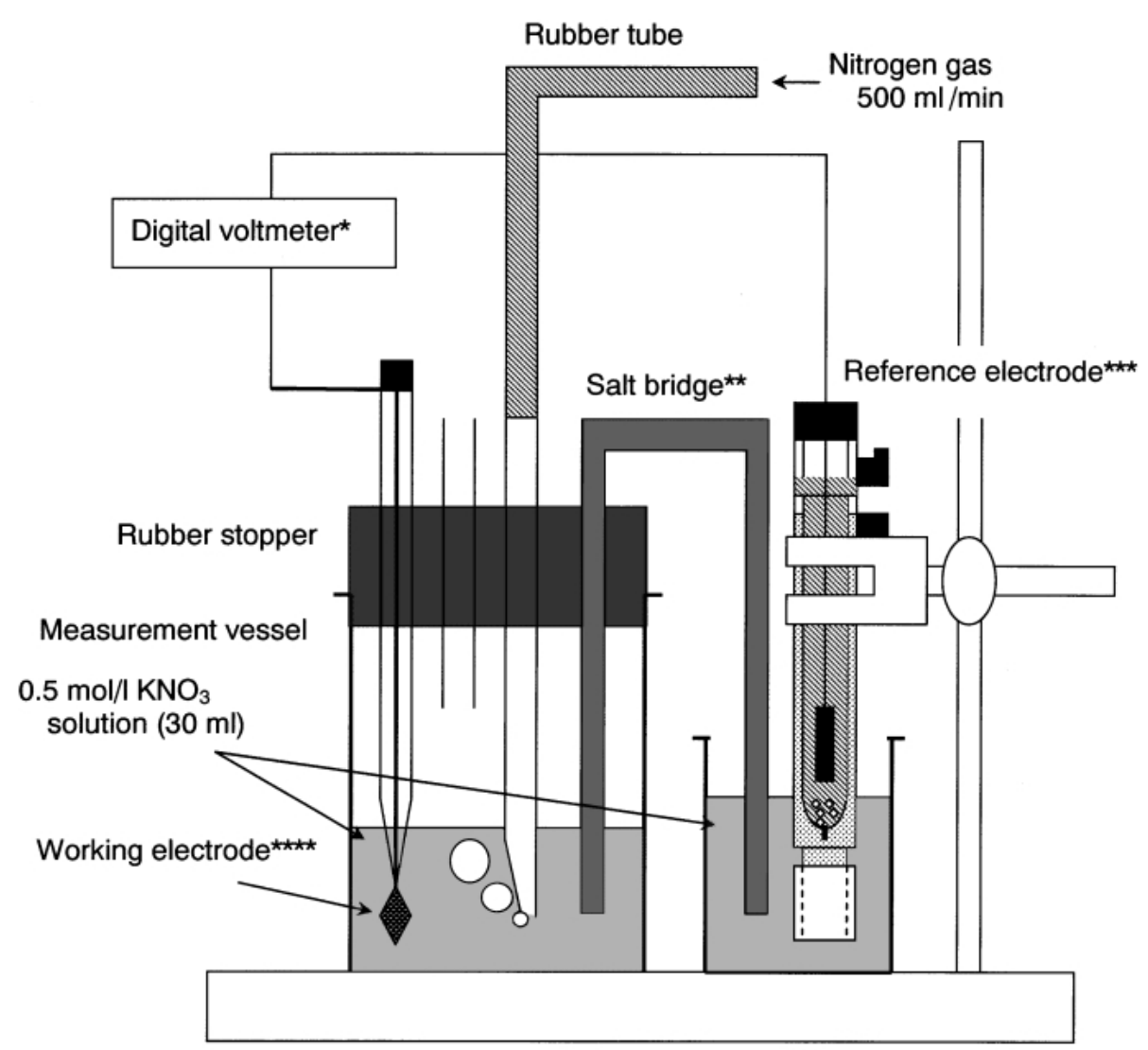

*Commercially available digital voltmeter.

* Salt bridge was prepared using $\mathrm{KNO}_{3}$

*** Reference electrode was $\mathrm{Ag} / \mathrm{AgCl}$ in saturated $\mathrm{KCl}$

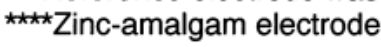

Fig. 2. Experimental Apparatus for the Zinc Amalgam Method

Table 2. Stock Solution of Drugs

\begin{tabular}{lccl}
\hline \hline \multicolumn{1}{c}{ Drug } & $\begin{array}{c}\text { Concentration } \\
\text { mol/l }\end{array}$ & $\begin{array}{c}\text { Added volume** } \\
\text { ml }\end{array}$ & \multicolumn{1}{c}{ Solvent* } \\
\hline Penicillamine & 0.150 & 0.2 & Aq, Et, DMF \\
Diclofenac sodium & 0.043 & 0.7 & Aq, Et, DMF \\
Carbamazepine & 0.075 & 0.4 & Et, DMF \\
Enalapril maleate & 0.030 & 1.0 & Aq, Et, DMF \\
Furosemide & 0.038 & 0.8 & Et, DMF \\
Amoxicillin & 0.030 & 1.0 & DMF \\
Propylthiouracil & 0.100 & 0.3 & DMF \\
Cyclophosphamide & 0.038 & 0.8 & Aq, Et, DMF \\
Fluorouracil & 0.075 & 0.4 & Aq, DMF \\
Acetazolamide & 0.060 & 0.5 & DMF \\
Captopril & 0.050 & 0.6 & Aq, Et, DMF \\
Bezafibrate & 0.038 & 0.8 & Aq, Et, DMF \\
Cyanamide & 0.030 & 0.1 & Et, DMF \\
Ibuprofen & 0.050 & 0.6 & Et, DMF \\
Amlodipine besilate & 0.030 & 1.0 & Aq, Et \\
$L$-cysteine*** & 0.150 & 0.2 & Aq \\
$L$-alanine*** & 0.150 & 0.2 & \\
\hline
\end{tabular}

${ }^{*}$ Solvent dissolved was $\mathrm{Aq}\left(\mathrm{H}_{2} \mathrm{O}\right)$, Et (ethanol), and DMF. ${ }^{* *}$ The volume was dissolved in test solution of $30 \mathrm{ml}$.

*** Stability constant with $\mathrm{Zn}^{2+}$ is reported in aqueous solution. 
in two steps. The drugs were dissolved in ethanol or $N, N$-dimethylformamide (DMF) to prepare each concentrated solution in advance. The stock solution was dissolved in $\mathrm{KNO}_{3}$ solution to prepare the test solution.

Acetazolamide, allopurinol, amoxicillin, bezafibrate, captopril, carbamazepine, ciprofloxacin, cyanamide, cyclophosphamide, diclofenac sodium, enalapril maleate, fluorouracil, furosemide, ibuprofen, miconazole, ofloxacin, penicillamine and propylthiouracil were supplied by Wako Pure Chemical Industries, Ltd. Amlodipine besilate was obtained in bulk from Sumitomo Pharmaceutical Co., Ltd. Candesartan cilexetil was obtained in bulk from Takeda Chemical Industries, Ltd.

Potential Measurement The electrode potential was measured using the experimental apparatus shown in Fig. 2. Nitrogen gas was passed through the solution for $15 \mathrm{~min}$ to remove the dissolved oxygen with a flow rate of $500 \mathrm{ml} / \mathrm{min}$. The stock solution of $3 \times 10^{-2} \mathrm{~mol} / 1 \mathrm{Zn}\left(\mathrm{NO}_{3}\right)_{2}$ was added to the test solution to adjust the concentration of $\mathrm{Zn}^{2+}$ to $5.0 \times$ $10^{-4} \mathrm{~mol} / 1$.

In the case of water-soluble drugs, aqueous solution was added to adjust the concentration of drug to $1.0 \times 10^{-3} \mathrm{~mol} / 1$, and the electrode potential was measured first. Then the concentration of the drug was increased to $2.0 \times 10^{-3} \mathrm{~mol} / 1$ and $3.0 \times 10^{-3}$ $\mathrm{mol} / 1$ successively, and the electrode potential was measured at each concentration. In the case of waterinsoluble drugs, the electrode potential of $\mathrm{Zn}^{2+} /$ $\mathrm{Zn}(\mathrm{Hg})$ in $30 \mathrm{ml}$ of electrolyte solution $(0.5 \mathrm{~mol} / 1$ $\mathrm{KNO}_{3}$ ) containing $4 \mathrm{ml}$ of each organic solvent was measured in advance without adding drug solution to confirm the instrumental stability because it was feared that organic molecules would adsorb chemically on the amalgam electrode. After stabilizing the electrode potential, each stock solution was added to the test solution to adjust the concentration of drug to $1.0 \times 10^{-3} \mathrm{~mol} / \mathrm{l}$. Then the concentration was increased to $2.0 \times 10^{-3} \mathrm{~mol} / 1$ and $3.0 \times 10^{-3} \mathrm{~mol} / 1$ successively, similar to the watersoluble drugs. In the present study, no drug showed a theoretical Nernst slope. Thus the potential difference with the first drug addition of $1.0 \times 10^{-3} \mathrm{~mol} / 1, \Delta E_{2}$, was adopted as a measure of the chelating ability of a drug with $\mathrm{Zn}^{2+}$.

Multivariate Analysis Using JMP ${ }^{\circledR} \quad \mathrm{JMP}^{\circledR}$ is a powerful statistical software package provided by
SAS Institute Inc., USA. Discriminant and multiple regression analyses were conducted using the $\mathrm{JMP}^{\circledR}$ program. The parameters used were the drug information described in package inserts and interview forms as well as observed chelating ability.

\section{RESULTS}

Zinc Amalgam Method The Nernst plot of the $\mathrm{Zn}^{2+} / \mathrm{Zn}(\mathrm{Hg})$ system was measured prior to examining the chelating ability. The minimum concentration of $\mathrm{Zn}^{2+}$ was then determined to reduce the amount of drug added as much as possible. Figure 3 shows the observed Nernst plot of the $\mathrm{Zn}^{2+} / \mathrm{Zn}$ $(\mathrm{Hg})$ system in $0.5 \mathrm{~mol} / 1 \mathrm{KNO}_{3}$ solution. The plot agreed well with the Nernst equation between concentrations from $1.0 \times 10^{-1}$ to $1.0 \times 10^{-4} \mathrm{~mol} / 1$. The result suggested that the present apparatus was appropriate to evaluate the chelating ability of drugs with zinc ions according to Eqs. (2) and (6). From the results in Fig. 3, the concentration of $5.0 \times 10^{-4}$ mol/1 was selected for the potential measurement. The open circle and arrow in Fig. 3 indicate the position at which the chelating ability was measured.

\section{Electrode Potential Measurement}

The electrode potential of the $\mathrm{Zn}^{2+} / \mathrm{Zn}(\mathrm{Hg})$ system was then measured in the presence of a drug that was thought to chelate with zinc ions. If $\mathrm{Zn}^{2+}$ forms a 1 : 1 chelate with drug $\mathrm{L}$, i.e., $\mathrm{ZnL}^{2+}$, the

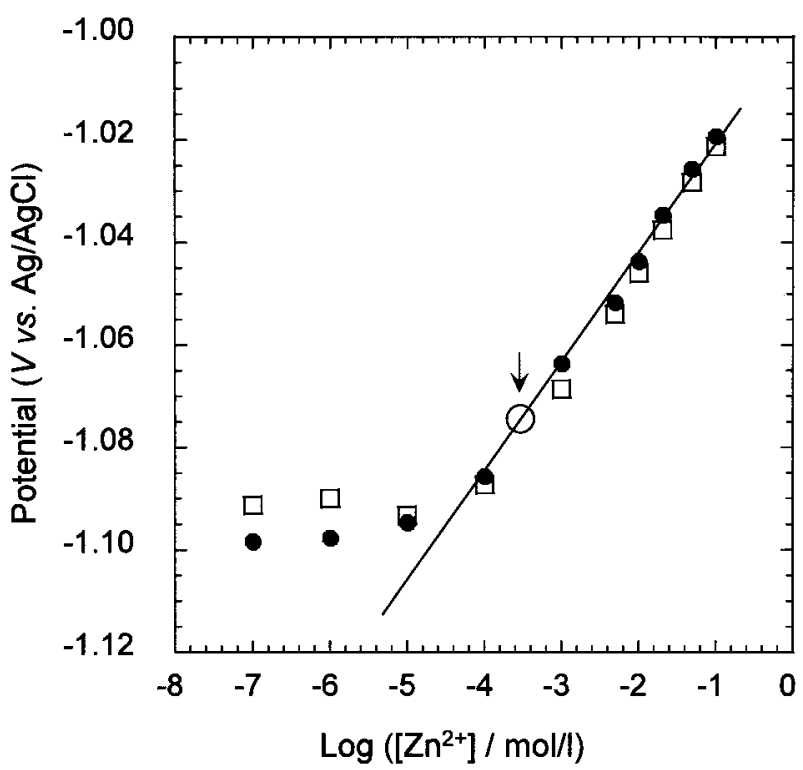

Fig. 3. Nernst Plot of the $\mathrm{Zn}^{2+} / \mathrm{Zn}(\mathrm{Hg})$ system Observed equation, $y=0.0294 x-0.9838\left(R^{2}=0.9991\right)$; theoretical Nernst equation, $y=0.0295 x-0.999\left(24^{\circ} \mathrm{C}\right)$ 
theoretical Nernst slope is $2.3 \times(R T / 2 F)$ according to Eq. (5) and the value is about $30 \mathrm{mV}$ at $25^{\circ} \mathrm{C}$. The Nernst slope was measured with the addition between $1.0 \times 10^{-3}$ and $2.0 \times 10^{-3} \mathrm{~mol} / 1$ of drug. If $\mathrm{Zn}^{2+}$ formed a $1: 1$ chelate with the drug, the actual concentration of drug was $0.5 \times 10^{-3}$ and $1.5 \times 10^{-3}$ because the solution contained $0.5 \times 10^{-3} \mathrm{~mol} / \mathrm{l}$ of $\mathrm{Zn}^{2+}$ and consumed the same amount of drug. If the actual concentration ratio was $0.5: 1.5$, the theoretical Nernst slope between the two concentrations was estimated to be $14 \mathrm{mV}$. The Nernst slope $\Delta E_{1}$ between the two concentrations is shown in Table 3. The observed slopes, however, were $3.1-5.6 \mathrm{mV}$. The result suggested a small stability constant and a large $\left[\mathrm{Zn}^{2+}\right] /[\mathrm{L}]$ ratio. Under such conditions, Eq. (5) is not satisfied and the estimation of the stability constant in Eq. (4) was unsuccessful.

Accordingly, the potential difference $\Delta E_{2}$ was measured between the drug concentrations of $0.0 \mathrm{~mol} / 1$ (without drug) and $1.0 \times 10^{-3} \mathrm{~mol} / 1$. Since the potential difference indicates the reduction in $\mathrm{Zn}^{2+}$ concentration due to chelate formation, $\Delta E_{2}$ was selected to evaluate the relative chelating ability instead of the absolute value of the stability constant. The results of the electrode potential measurement are summarized in Table 3.

When ethanol was used as a stock solution, a large potential change in $\Delta E_{2}$ was observed: $32.6 \mathrm{mV}$ for penicillamine, $25.3 \mathrm{mV}$ for furosemide, and $20.7 \mathrm{mV}$ for ibuprofen. Similarly, a large potential change was observed when DMF was used as a stock solution: $20.4 \mathrm{mV}$ for furosemide, $34.6 \mathrm{mV}$ for fluorouracil, $38.5 \mathrm{mV}$ for acetazolamide, $22.4 \mathrm{mV}$ for bezafibrate, and $17.4 \mathrm{mV}$ for ibuprofen. These data are used in the multiple regression analysis.

Multivariate Analysis It is important to extract any unknown parameters are related to taste

Table 3. F. Fukasawa, et al. Statistical Approach to the Drug-Induced Taste Disorders Based on Zinc Chelating Ability

\begin{tabular}{|c|c|c|c|c|c|c|c|c|c|c|}
\hline \multirow{3}{*}{ No. } & \multirow{3}{*}{ Drug name } & \multicolumn{9}{|c|}{ Solvent } \\
\hline & & \multicolumn{3}{|c|}{ Water } & \multicolumn{3}{|c|}{ Ethanol* $^{*}$} & \multicolumn{3}{|c|}{$N, N$-dimethylformamide ${ }^{* *}$} \\
\hline & & $\Delta E_{1} / \mathrm{mV}$ & $\Delta E_{2} / \mathrm{mV}$ & $\mathrm{pH}$ & $\Delta E_{1} / \mathrm{mV}$ & $\Delta E_{2} / \mathrm{mV}$ & $\mathrm{pH}$ & $\Delta E_{1} / \mathrm{mV}$ & $\Delta E_{2} / \mathrm{mV}$ & $\mathrm{pH}$ \\
\hline 1 & Penicillamine & 0.05 & 4.6 & 4.6 & 6.14 & 32.6 & 4.3 & & $\#$ & \\
\hline 2 & Diclofenac sodium & 3.89 & 1.2 & 6.7 & 5.45 & 8.2 & 6.2 & 4.47 & 1.5 & 7.1 \\
\hline 3 & Carbamazepine & & $\#$ & & 0.0 & 0.0 & 4.8 & 0.0 & 0.0 & 5.3 \\
\hline 4 & Enalapril maleate & 0.0 & 0.0 & 4.1 & 0.0 & 0.0 & 3.2 & 0.0 & 0.0 & 3.3 \\
\hline 5 & Furosemide & & $\#$ & & 5.76 & 25.3 & 3.7 & 3.93 & 20.4 & 3.5 \\
\hline 6 & Amoxicillin & & $\#$ & & & $\#$ & & 4.16 & 7.4 & 3.9 \\
\hline 7 & Propylthiouracil & & $\#$ & & & $\#$ & & 0.0 & 0.0 & 5.6 \\
\hline 8 & Cyclophosphamide & 0.0 & 0.0 & 5.0 & 0.0 & 0.0 & 6.1 & 4.96 & 2.4 & 7.0 \\
\hline 9 & Fluorouracil & 3.33 & 2.9 & 5.6 & & $\#$ & & 6.55 & 34.6 & 5.7 \\
\hline 10 & Acetazolamide & & $\#$ & & & $\#$ & & 5.28 & 38.5 & 5.2 \\
\hline 11 & Captopril & 0.0 & 0.0 & 3.1 & 0.0 & 0.0 & 3.3 & 3.58 & 6.0 & 3.4 \\
\hline 12 & Bezafibrate & & $\#$ & & & $\#$ & & 3.67 & 22.4 & 3.6 \\
\hline 13 & Cyanamide & 3.12 & 1.5 & 7.0 & 4.34 & 2.3 & 6.8 & 5.88 & 8.2 & 7.0 \\
\hline 14 & Ibuprofen & & $\#$ & & 3.81 & 20.7 & 3.9 & 5.07 & 17.4 & 3.9 \\
\hline 15 & Amlodipine besylate & & $\#$ & & 0.0 & 0.0 & 5.3 & 3.65 & 9.1 & 5.6 \\
\hline 16 & Baclofen & & $\#$ & & & $\#$ & & & $\#$ & \\
\hline 17 & Ofloxacin & & $\#$ & & & $\#$ & & & $\#$ & \\
\hline 18 & Ciprofloxacin & & $\#$ & & & $\#$ & & & $\#$ & \\
\hline 19 & Allopurinol & & $\#$ & & & $\#$ & & & $\#$ & \\
\hline 20 & Miconazole & & $\#$ & & & $\#$ & & & $\#$ & \\
\hline 21 & Candesaltan & & $\#$ & & & $\#$ & & & $\#$ & \\
\hline 22 & $L$-cysteine & 5.07 & 16.2 & 4.7 & 4.98 & 17.0 & 4.7 & & $\#$ & \\
\hline 23 & $L$-aranine & 6.56 & 23.7 & 6.4 & & $\#$ & & & $\#$ & \\
\hline
\end{tabular}

\# Medicines that were not dissolved in the solvent.

$\Delta E_{1}$, Potential difference in $\mathrm{Zn}^{2+} / \mathrm{Zn}(\mathrm{Hg})$ system between [Drug] $=1.0 \times 10^{-3}$ and $2.0 \times 10^{-3} \mathrm{~mol} / \mathrm{l} . \Delta E_{2}$, Potential difference in $\mathrm{Zn}{ }^{2+} / \mathrm{Zn}(\mathrm{Hg})$ system between $\left[\right.$ Drug] $=0.0$ and $1.0 \times 10^{-3} \mathrm{~mol} / 1$. ${ }^{*}$ Volume of test solution: ethanol $=30 \mathrm{ml}: 4 \mathrm{ml}$. ${ }^{* *}$ Volume of test solution: $N, N$-dimethylformamide $=30 \mathrm{ml}: 4 \mathrm{ml}$ 
disorders. Multivariate analysis was first conducted on the package inserts using $\mathrm{JMP}^{\circledR}$ software. Two types of multivariate analysis were conducted. One is discriminant analysis that is effective in extracting significant parameters among various unknown parameters. The other the multiple regression analysis that can estimate the degree of taste disorder quantitatively for the parameters extracted in discriminant analysis.

\section{Discriminant Analysis of Package Insert Information}

Discriminant analysis is a type of multivariate analysis in which the equation and the variable are established to explain the objective variables (explanatory variables) of category data as well as the probability. ${ }^{15)}$ Using the analysis, significant variables can be extracted as the categorical frequency of taste disorders depending on the frequency greater than $0.1 \%$ and less than $0.1 \%$. The explanatory variables adopted in this study are shown in Table 4. The frequency of taste disorders among 110 internal drugs was examined stepwise using discriminant analysis. The first stepwise test was conducted to extract the effective variable and obtain the most suitable discriminant equation. In this method, a $P$ value of less than 0.05 was used to evaluate the significant explanatory variables.

In the first stepwise test, the maximum dose (g/day) with $P=0.0004$ and $-\mathrm{SO}_{2}-$ group with $P=$ 0.0414 were extracted, as shown in Table 5. The highest dose of drug per day given in package inserts was considered to be the maximum dose. The extracted variables were then discriminated using oneway layout analysis between the groups with a high (greater than $0.1 \%$ ) and a low (less than $0.1 \%$ ) frequency as stated in the package inserts. In the case of the maximum dose, the $P$ value was 0.0063 . In the case of the $-\mathrm{SO}_{2}-$ group, one-way analysis was impossible because the variable was not a numerical value but only 0 (without $-\mathrm{SO}_{2}-$ group) and 1 (with $-\mathrm{SO}_{2}-$ group).

Then 110 drugs were classified into the watersoluble group (43 drugs) and water-insoluble group (67 drugs) in the second stepwise test. In the case of water-soluble drugs, molecular weight and median dose (g/day) were extracted as effective variables, and $P$ values were 0.0187 and 0.0414 , respectively. Median dose was defined as the middle value between the maximum dose and the minimum dose in the
Table 4. Explanatory Variables in the Present Study

Molecular weight $(\mathrm{g} / \mathrm{mol})$, Water solubility, Minimum dose (g/day), Median dose (g/day), Maximum dose (g/day), Functional groups $\left(\mathrm{R}-\mathrm{COOH}, \mathrm{R}_{2}-\mathrm{NH}-\mathrm{Cl}, \mathrm{R}-\mathrm{S}-\mathrm{R}\right.$, $\mathrm{NR}_{3}, \mathrm{R}_{2}-\mathrm{C}=\mathrm{O}, \mathrm{R}-\mathrm{O}-\mathrm{R}, \mathrm{R}-\mathrm{O}-\mathrm{NR}_{2}, \mathrm{R}-\mathrm{COO}-\mathrm{R}, \mathrm{R}_{2}$ $\mathrm{C}=\mathrm{N}-\mathrm{O}-\mathrm{R},-\mathrm{OH}, \mathrm{R}-\mathrm{CONH}-\mathrm{R},-\mathrm{SH},-\mathrm{NO}_{2}, \mathrm{R}_{2} \mathrm{C}=$ $\mathrm{N}-\mathrm{R}, \mathrm{R}_{2}-\mathrm{C}=\mathrm{S},-\mathrm{NH}_{2},-\mathrm{SO}_{2}-, \mathrm{R}_{2}-\mathrm{C}=\mathrm{S}, \mathrm{R}_{2} \mathrm{C}=\mathrm{N}-\mathrm{O}$ $-\mathrm{R}, \mathrm{R}_{2} \mathrm{C}=\mathrm{N}-\mathrm{R}$ )

Table 5. Summary of Discriminant Analysis

\begin{tabular}{|c|c|c|}
\hline \multirow{2}{*}{ Variable } & \multicolumn{2}{|c|}{$P$ value* } \\
\hline & First step & Second step \\
\hline $\begin{array}{l}\text { Maximum dose (g/day) } \\
\text { (110 drugs) }\end{array}$ & 0.0004 & 0.0063 \\
\hline $\begin{array}{l}-\mathrm{SO}_{2}-\text { group } \\
\text { (110 drugs) }\end{array}$ & 0.0414 & - \\
\hline $\begin{array}{l}\text { Molecular weight }(\mathrm{g} / \mathrm{mol}) \\
\text { (43 water-soluble drugs) }\end{array}$ & 0.0187 & 0.0030 \\
\hline $\begin{array}{l}\text { Median dose (g/day) } \\
\text { (43 water-soluble drugs) }\end{array}$ & 0.0414 & $\begin{array}{l}0.1404 \\
(>0.05)\end{array}$ \\
\hline $\begin{array}{l}\text { Maximum dose (g/day) } \\
\text { (67 water-insoluble drugs) }\end{array}$ & 0.0040 & 0.0063 \\
\hline $\begin{array}{l}-\mathrm{SO}_{2}-\text { group } \\
\text { (67 water-insoluble drugs) }\end{array}$ & 0.0065 & - \\
\hline
\end{tabular}

package inserts. The extracted variables were then discriminated. In case of molecular weight, the $P$ value was 0.0030 , as shown in Fig. 4 (a). Drugs with a high frequency had molecular weight of less than 350. In other words, water-soluble drugs with a low molecular weight should be considered as a cause of drug-induced taste disorders. The median dose, however, was not significant because the $P$ value was 0.1404, as shown in Fig. 4(b). The result indicates that median dose is not a discriminant variable. For water-insoluble drugs, the $P$ value of the maximum dose and $-\mathrm{SO}_{2}-$ group were 0.0040 and 0.0065 , respectively. The extracted variables were then discriminated. The result is shown in Fig. 4 (c) . The $P$ value of the maximum dose was significant at 0.0063 .

Table 5 shows a summary of the discriminant analysis. The results for the maximum dose are reasonably acceptable. The significance of low molecular weight is accountable because the unit of weight in grams or milligrams is used in pharmaceutical administration, while the effect of a drug depends on the amount of drug in mol. As the 

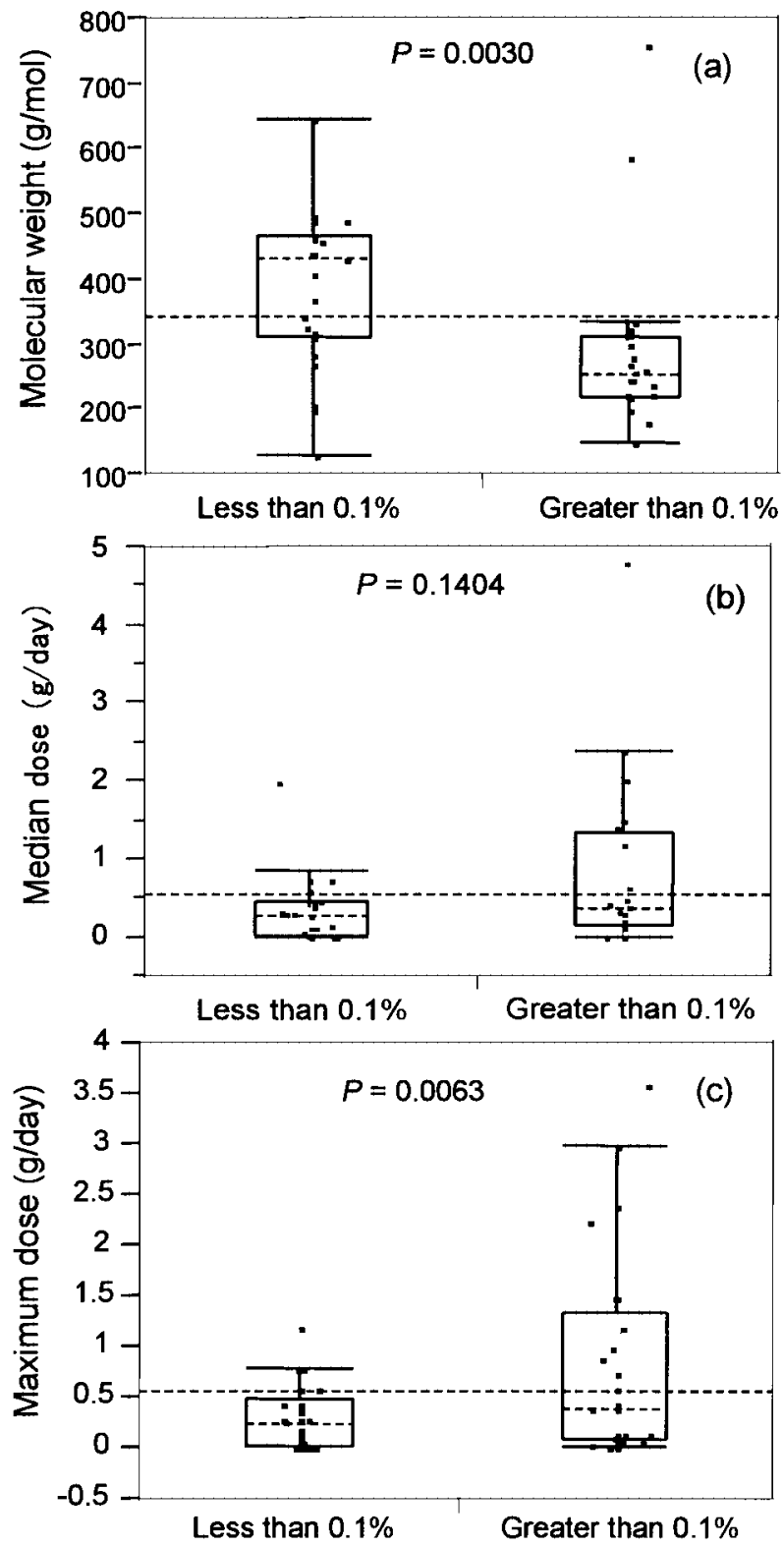

Categorical frequency of taste disorders

Fig. 4. Relationship between Categorical Frequency of Druginduced Taste Disorders (JMP Output)

Molecular weight in water-soluble drugs (a), median dose (g/day) in water-soluble drugs (b), and maximum dose $(\mathrm{g} / \mathrm{mol})$ in water-insoluble drugs (c)

molecular weight decreases, the amount of drug increases at the same weight. Among functional groups that were thought to form a chelate compound with zinc ions, only the $-\mathrm{SO}_{2}-$ group was extracted as a significant valuable. The tendency was then examined using the zinc-amalgam method.

\section{Multiple Regression Analysis of Observed Chelating Ability of Drugs}

In multiple regression analysis, the objective
Table 6. $F$ Values and $P$ Values for Four Variables in Multiple Regression Analysis

\begin{tabular}{lcccccc}
\hline \hline \multirow{2}{*}{ Variable } & \multicolumn{2}{c}{ First step } & & \multicolumn{2}{c}{ Second step } \\
\cline { 2 - 3 } \cline { 6 - 7 } \cline { 5 - 6 } & $F$ value* $^{*} P$ value & & $F$ value* & $P$ value \\
\hline Chelating ability & 3.269 & 0.2124 & & 3.269 & 0.2124 \\
Molecular weight & 0.218 & 0.6867 & & 0.208 & 0.7278 \\
Maximum dose & 3.210 & 0.2151 & & 0.002 & 0.9750 \\
Solubility (JP14) & 1.259 & 0.3784 & & 0.162 & 0.7562 \\
\hline
\end{tabular}

${ }^{*} F$ value greater than 2.0 were considered to be significant.

variable is established using explanatory variables. ${ }^{15)}$ Frequency of taste disorders was the objective variable in the present study. Based on the discriminant analysis, the explanatory variables selected were the chelating ability in DMF, molecular weight, maximum dose, and solubility of four drugs for which the zinc-chelating ability could be measured in this study and the value of the frequency of taste disorders was available on interview forms, i.e., diclofenac sodium, enalapril maleate, cyclophosphamide, and acetazolamide.

The multiple regression analysis was conducted using the stepwise test to extract the effective explanatory variables and deduce the most suitable regression equation. An $F$ value larger than 2.0 is generally significant. ${ }^{15)}$ The stepwise test is repeated until all $F$ values become less than 2.0. The results of the stepwise test are shown in Table 6. In the first step, chelating ability showed the highest $F$ value and was extracted as the explanatory variable. The $F$ value was 3.269 and $P$ value was 0.2124 . In the second step, the test was terminated because there was no variable larger than 2.0 except for chelating ability. JMP output of the regression equation for the present system regarding chelating ability was:

Frequency of taste disorder (\%)

$$
=0.044992+0.002194 \times(\text { chelating ability } / \mathrm{mV})
$$

The equation indicates the quantitative frequency of taste disorders that depend on the zinc-chelating ability as a superior explanatory variable.

The frequency of taste disorders was estimated from the regression equation of JMP output, Eq. (7), for 14 drugs for which zinc-chelating ability was first measured in this study. The frequency could also be estimated for the drugs marked "unclear" in package inserts and interview forms. The estimated frequency of taste disorders is summarized in Table 7 
Table 7. Comparison of Frequency Appearing in Package Inserts and Interview Forms ${ }^{14,15)}$ with Estimated Frequency Calculated Using Eq. (7)

\begin{tabular}{lllc}
\hline \hline \multicolumn{1}{c}{ Drugs } & $\begin{array}{c}\text { Categorical } \\
\text { frequency in } \\
\text { package inserts }\end{array}$ & $\begin{array}{c}\text { Frequency in } \\
\text { interview forms } \\
(\%)\end{array}$ & $\begin{array}{c}\text { Estimated } \\
\text { frequency } \\
(\%)\end{array}$ \\
\hline Diclofenac sodium & $<0.1 \%$ & 0.003 & 0.048 \\
Carbamazepine & Unclear & No mention & 0.045 \\
Enalapril maleate & $<0.1 \%$ & 0.07 & 0.045 \\
Furosemide & Unclear & No mention & 0.091 \\
Amoxicillin & Unclear & No mention & 0.061 \\
Propylthiouracil & Unclear & No mention & 0.045 \\
Cyclophosphamide & $0.1-5.0 \%$ & 0.07 & 0.050 \\
Fluorouracil & $<0.1 \%$ & No mention & 0.121 \\
Acetazolamide & $0.1-5.0 \%$ & 0.13 & 0.129 \\
Captopril & $0.1-5.0 \%$ & No mention & 0.058 \\
Bezafibrate & Unclear & No mention & 0.094 \\
Cyanamide & Unclear & No mention & 0.063 \\
Ibuprofen & Unclear & No mention & 0.083 \\
Amlodipine besylate & Unclear & No mention & 0.065 \\
Penicillamine* & $0.1-5.0 \%$ & 1.84 & - \\
\hline
\end{tabular}

* Electrode potential could not be measured using DMF.

together with those of the categorical frequency in package inserts and interview forms. The concordance between the frequency in package inserts and estimated values was $50 \%$.

Penicillamine has the highest frequency in interview forms. In this study, the zinc-chelating ability of penicillamine could not be estimated because the potential difference $\Delta E_{2}$ could not be measured due to its low solubility in DMF. The observed potential difference of penicillamine in aqueous and ethanol solutions, however, was fairly large in comparison with those of other drugs, as expected from the value in interview forms. Accordingly, the estimated frequency for penicillamine would be large if the multiple regression analysis were applied.

\section{DISCUSSION}

To examine the possibility of introducing the multivariate analysis, the data on the zinc-chelating ability of 14 drugs in Table 7 were applied to clinical cases of taste disorder patients. The results of the authors' search of previous records on taste disorders in Kanto Medical Center are shown in Fig. 5. It was found that drug-induced taste disorders occur more often in advanced age. An example was extracted from the search results which could illustrate the data in Table 7. Figure 6 shows the medication history of a

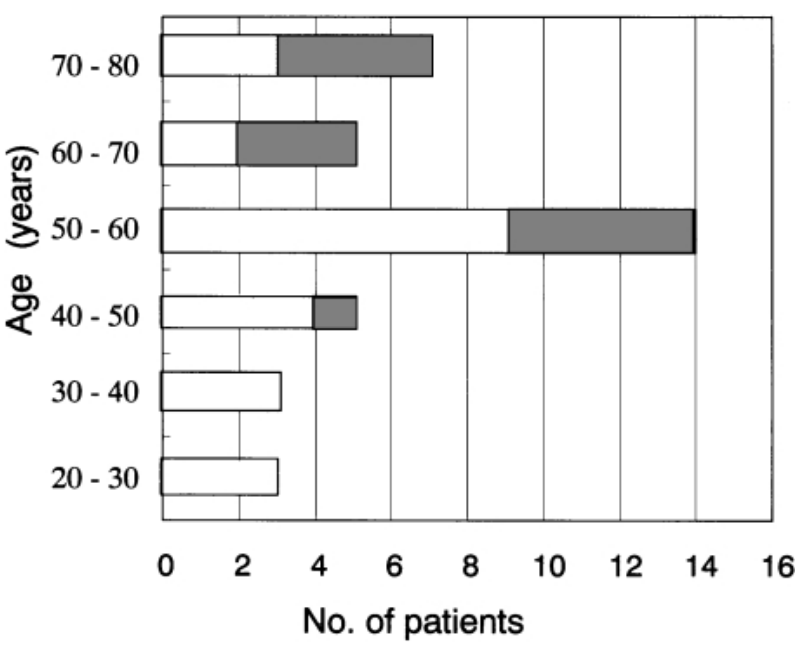

Fig. 5. Age Distribution and Drug Induced Taste Disorders (Meshed Area) of 37 Taste Disorder Patients in the Kanto Medical Center NTT EC

patient. The reported symptoms were "lack of taste" and "bad-tasting food." The patient continued to report a taste disorder for about 4 months. Four drugs were administered during the first 4 months: benzbromarone, amlodipine besilate, enalapril maleate, and bezafibrate. On March 19, the serum concentration of zinc was measured as part of general therapy for taste disorders. ${ }^{16)}$ The value was $0.63 \mathrm{mg} /$ 1 , compared with normal range of $0.59-1.35 \mathrm{mg} / 1$. The administration of polaprezinc, ${ }^{17)}$ however, was 
Date / month

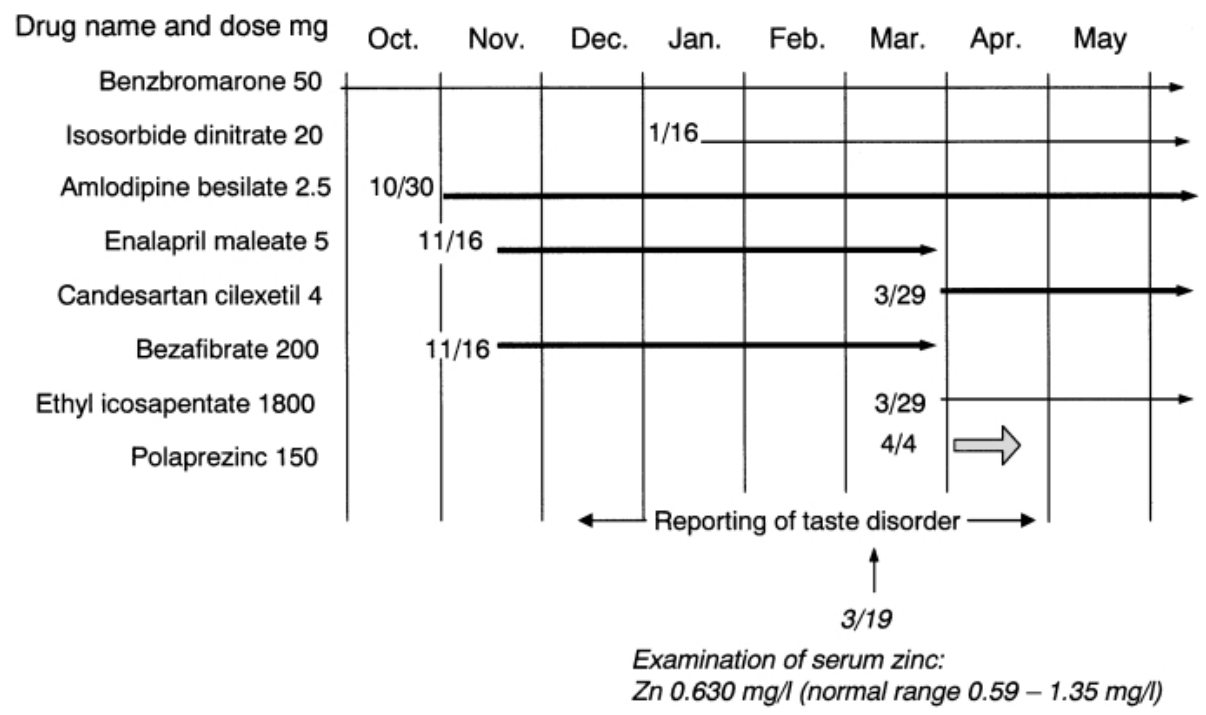

Fig. 6. Medication History of a Patient with Taste Disorder

delayed until April 4 although an other typical zinc agent for the treatment of taste disorder, zinc sulfate, was available. ${ }^{18)}$ On the other hand, the administration of bezafibrate was terminated on March 29 because the patient showed low renal function. After these treatments, his taste disorder resolved in late April.

Assuming that the cause of the taste disorder was zinc deficiency related to the chelation ability ${ }^{12)}$ of prescribed drugs, bezafibrate was the likeliest candidate for the taste disorder among the four drugs administered because it showed the largest frequency of 0.094 as deduced from the potential change of 22.4 $\mathrm{mV}$. The potential changes of amlodipine besilate and enalapril maleate were $9.1 \mathrm{mV}$ and $0.0 \mathrm{mV}$, respectively. Thus the possibility that amlodipine besilate and enalapril maleate caused the disorder appeared low or intermediate. Benzbromarone was excluded for convenience because the potential change could not be measured in this study.

Within the limits of this study, no definite conclusion was made because the time at which the administration of bezafibrate was terminated and the time of the administration of the zinc agent overlapped. However, earlier treatment of taste disorders would be possible if suggestions were given to physicians on the zinc-chelating ability.

\section{CONCLUSION}

1) The electrode potential of the $\mathrm{Zn}^{2+} / \mathrm{Zn}(\mathrm{Hg})$ system in the presence of drugs was measured using the potentiometric zinc amalgam method in water, ethanol, and DMF. The potential change $\Delta E_{2}$ with the addition of the drug was measured to reflect the zinc-chelating ability of drugs.

2) A large potential change that indicated potent chelating ability was observed for penicillamine, furosemide, and ibuprofen in ethanol and for fluorouracil, acetazolamide, and bezafibrate in DMF. 3) Maximum dose, molecular weight of watersoluble drugs, and $-\mathrm{SO}_{2}-$ functional group were extracted as significant variables in drug-induced taste disorders based on the results of discriminant analysis.

4) The frequency of drug-induced taste disorders as an objective variable was estimated using multiple regression analysis for which chelating ability, molecular weight, maximum dose, and solubility in water were selected as the explanatory variables. The most effective factor was chelating ability in the stepwise test.

5) The regression equation to estimate the frequency of taste disorders was deduced on the basis of the potential change $\Delta E_{2}$ (chelating ability) and the frequency for four drugs that had already been reported in interview forms. Based on the regression equation, the frequency of taste disorders was estimated for 14 drugs examined in this study.

\section{ACKNOWLEDGMENT}

Authors wish to thank Sumitomo Pharmaceuticals Co., Ltd. and Takeda Chemical Ind., Ltd. who 
kindly provided us amlodipine besilate and candesartan, respectively.

\section{REFERENCES}

1) “Taber's Cyclopedic Medical Dictionary," F. A. Davis Company, USA, 1997.

2) Trevor M. S., Nicholas H. G., "Avery's Drug Treatment," Adis International, 1997, p. 626.

3) Hamada N., Endo S., Tomita H., Acta Otolaryngol. Suppl., 546, 7-15 (2002).

4) "Drugs in Japan DB CD-ROM (April 2002)," Japan Pharmaceutical Information Center and Jiho, Tokyo, 2002.

5) Prasad A. S., Halsted J. A., Nadimi M., Am. J. Med., 31, 532-546 (1961).

6) Prasad A. S., Miale Jr. A., Farid Z., Sandstead H. H., Schulert A. R., J. Lab. Clin. Med., 61, 537-549 (1963).

7) Tarui S., Nihon Rinsho, 16, 2071-2086 (1958).

8) Tarui S., Med. J. Osaka Univ., 10, 499-505 (1960).

9) Henkin R. I., Bradly D. F., Life Sci., 9, 701709 (1970).

10) Sekimoto K., Tomita H., Nihon Univ. Med.,
28, 233-252 (1986).

11) Haga M., Tomita H., Micrometal Metab., 7, 41-52 (1979).

12) Tomita H., Nihon Rinsho, 54, 141-147 (1996) .

13) Tomita H., Geriatric Med., 39, 199-210 (2001).

14) Package inserts and interview forms of: penicillamine, diclofenac sodium, carbamazepine, enalapril maleate, furosemide, amoxicillin, propylthiouracil, cyclophosphamide, fluorouracil, acetazolamide, captopril, bezafibrate, cyanamide, ibuprofen, amlodipine besilate, candesartan cilexetil, miconazole, allopurinol, ciprofloxacin, ofloxacin.

15) Engawa T., "Tahenryo no Data Kaiseki," Asakura Shoten, Tokyo, 1988, pp. 22-67.

16) Yanagisawa H., Kurihara N., Wada O., Nippon Rinsho, 57, Suppl. 282-286 (1999) .

17) Ikui A. Ikeda M., Yoshikawa T., Kudo I., Onoda K., Kida A., Jibi-inkouka Rinsho, 92, 801-804 (1999) .

18) Henkin R. I., Schecter P. J., Friedeweld W. T., Demets D. L., Raff M., Am. J. Med., 272, 285-299 (1976). 